\title{
Spatial and Annual Variation of Offshore Wind Resource in China
}

\author{
Litao Ge, Takanori Uchida, Yuji Ohya \\ Kyushu University, Fukuoka, Japan \\ Email: litao@riam.kyushu-u.ac.jp
}

Received 10 April 2014; revised 10 May 2014; accepted 17 May 2014

Copyright (C) 2014 by authors and Scientific Research Publishing Inc.

This work is licensed under the Creative Commons Attribution International License (CC BY).

http://creativecommons.org/licenses/by/4.0/

(c) (i) Open Access

\begin{abstract}
According to the Chinese "Twelfth Five-Year Plan", two large scale wind farms are planned to be built in the shore of Shandong province and Guangdong province to meet the increasing electricity demand with economic development. Before the construction of wind farm, it is necessary to evaluate the wind potential and its temporal variation along the coast of Shandong province, Guangdong province and Zhejiang province that have been studied in this paper. The data used were obtained from Goddard Earth Observing System (GEOS) Data Assimilation System. The results showed that there is rich wind supply in Zhejiang province with small annual variation. Further away from shore, the wind energy will increase fastest in Guangdong area. The yield of wind energy in Shandong province is not as rich as in the other two provinces as predicted in the study. Furthermore, the layout of wind turbines in wind farm was also investigated to absorb wind energy at the highest efficiency by wind farm. Our results provide a reference for the future construction of wind farms.
\end{abstract}

\section{Keywords}

Offshore Wind Power, Variation, Reanalysis Data

\section{Introduction}

In recent years, the Chinese economy is growing at a high speed of 8\%. Energy demand also has been correspondingly increased to satisfy this development, especially in the east coastal advanced area. Oil, coal, and gas are the traditional energy sources. However, the availability of these sources is limited. Many researchers have estimated that the oil resource will run out and the coal resource will be depleted. Thus, energy issues will be an expected challenge for China in the future and have far reaching impact for the sustainable development.

Nowadays, more and more scientists are making an effort to explore the renewable energy, including solar, 
geothermal and wind energy [1]-[3]. Among these, wind energy is clean and has promising exploitation prospect. According to investigations, China has abundant wind power resources with great potentiality for exploration. Wind power resources mount to app. 0.6 - 1 bil kW on land, app. 0.2 bil kW on sea [4]. At height of over $50-60 \mathrm{~m}$, the wind resource is even greater. If $1 / 2$ of this energy is exploited, app. 0.5 bil $\mathrm{kW}$ will be provided. It may significantly compensate the energy demand gap in 2050 power demand.

In the present condition, most wind farms were built in Gansu, Heilongjiang provinces which are far away from the high electricity consumption area. The charge for long distant electricity transmission is high. CNY 1 cent/KWh when the distant is less than $50 \mathrm{KM}$; CNY 2 cent/KWh when the distant is longer than $50 \mathrm{KM}$ and less than $100 \mathrm{KM}$, CNY 3 cent/KWh when the distant is longer than $100 \mathrm{Km}$. So, building wind farm in East China Sea can save far distant transmission fee and prevent the energy loss during the electricity transmission. Therefore, the China government has announced the policy of development of offshore wind farm plan and has written the construction of wind farm in Shandong and Guangdong provinces in the 12th five-year plan [5].

The cost is the main factor needing to be considered before construction of wind farm in developing country. Wind farm should be built depending on its availability, and also affordability needs to be considered. Any inefficiency of electricity usage will cause higher costs, which the grid company will transfer to the consumer. The wind energy potential and its fluctuation need to be researched before construction of offshore wind farm. This will benefit for planning electricity generation at given time and electricity distribution network. The Carbon Dioxide Mechanism (CDM) could also be a method of reducing the cost for building wind farms in developing countries with financial and technological help from developed countries [6]. The accurate prediction of wind potential and temporal variation of wind energy is one of the dominant factors for the registration of CDM. If the favorable costs of generating electricity of wind energy can be reached, investments will be easily attracted in wind energy.

Xu Jingwei etc. have done the research of the potential China Offshore Wind Energy Resources based on the data from Sea Winds scatter meter on board the National Aeronautics and Space Administration (NASA) QuikSCAT satellite which is remote sensing data [7]. Xiang Fang has studied the offshore wind potential and compared the result with results based on data from the boat observation [8]. However, current researches are not sufficient to guide the exploration of the rich offshore wind resource, much more research needs to be done to improve the accuracy of wind resource and how it varies in different places and different seasons.

\section{Introduction of the Data Used in the Study}

Very few wind measurement masts are in the sea, and most of them are set up in near shore areas. Because of that very few measured wind speed are available to assess the wind energy off shore, especially at the latitude of $80 \mathrm{~m}$ or above which is the hub height of modern wind turbine for making use of offshore wind power. This lack of data is the reason why the accurate offshore wind potential could not have been fully and completely studied. Instead of meteorological observation data, reanalysis data provide another way of researching the wind potential and variation.

The data was provided by the Goddard Earth Science Data and Information Service Center of National Aeronautics and Space Administration, which a retrospective analysis for the satellite era using a major the Goddard Earth Observing System (GEOS) Data Assimilation System [9]-[11]. The data comes from reanalysis of observational data measured by aircrafts, balloons, ships, buoys and satellites. Ten years data from 2001 to 2011 was used in this paper. The spatial resolution of the data is 0.5 degree in latitude direction and 0.67 degree in longitude direction. The wind speed at altitude of $71 \mathrm{~m}$ was used for this analysis. The four-hours averaged wind speed data was employed in this study.

Comparison of GEOS data and measured data in Liaoning area (inland area) have been done to test the tendency of the daily changes of wind speed by monitoring the output of wind turbine, and the result shows that GEOS data have good consistency with measured data [10]. The accuracy of wind speed in the sea needs to be tested to make clear the error of the assessment. Different data resources did its analysis to find their advantages and disadvantage separately.

Observational data can be obtained from China Meteorological Administration's Observations Station Data. One of the data set which was measured in Bohai Sea $\left(38.45^{\circ} \mathrm{N}, 118.42^{\circ} \mathrm{E}\right)$ was chosen for comparing because the Bohai Sea area of Shandong province is less suffering the strike of the strong storm than other two places researching in this paper. Other compared data sources are QuikSCAT Data, Numerical Weather Product Data. 
Although there are other three data resources available, which are Japanese 25-year reanalysis data of wind speed from JMA Climate Data Assimilation System (JCDAS), ERA-40 provided by European Centre for Medium-Range Weather Forecasts and JRA-25. The resolutions are not as detailed as the kinds of data used in our study. The QuikSCAT Data is product of Jet Propulsion Laboratory of California Institute of Technology (Caltech) and National Aeronautics and Space Administration (NASA). Its spatial resolution is $12.5 \mathrm{~km}\left(0.1^{\circ}\right)$ both in latitude direction and longitude direction with an accuracy of $0.1 \mathrm{~m} / \mathrm{s}$. QuikSCAT Data provides two different results by two inversion methods which are Ambiguity Removal algorithm (A.R.) and DIRTH Algorithms (DIRTH). The data of Numerical Weather Product was from National Center for Environmental Prediction (NCEP).

The parameters compared are closely related with predicting the output of electricity from wind energy, which are speed standard deviation, mean speed, shape parameter $\mathrm{k}$ of Weibull distribution, scale parameter c of Weibull distribution.

The Table 1 depicts that data from the GEOS fits well the observational data and can be used to do assess the wind potential in offshore area with smaller error than other data resources.

\section{Methodology}

In this paper, average daily wind speed was calculated first, and then calculation of monthly wind energy was done based on average daily wind speed. After that we obtained potential wind energy changes with distance away from coast after averaging twelve month wind energy in research area.

The wind speed data is at an altitude of approximately $71 \mathrm{~m}$ [11]. High-power wind turbine quipped for the offshore wind farm is designed to be more than 5 MW. Recently 6 MW and 7.5 MW have been manufactured. And research institute in the world are investigated in $10 \mathrm{MW}$. Currently, $3 \mathrm{MW}$ wind turbine is widely used in offshore wind farm whose hub height is approximately $80 \mathrm{~m}$.

By interconnecting wind farm in some area, output of array of wind farms can be taken as similarly to a single farm [12]. Then the output of one turbine of this area was calculated to predict the characteristics as a representative for the output of the wind farm in an area.

The wind energy that can be converted into electricity can be calculated by the Equation (1)

$$
P=\frac{1}{8} \alpha \rho \pi D^{2} V_{80}^{3}
$$

where, $P$ refers to wind energy converted into electricity, $a$ is the efficiency of the wind turbine, $\rho$ is the density of the air, $D$ is the diameter of the wind turbine, $V_{80}$ is wind speed at 80 meters height, $\pi$ is 3.14.

$$
\alpha=c_{1}\left(\frac{c_{2}}{\lambda}-c_{3}-c_{4}\right) e^{\frac{-c_{5}}{\lambda_{i}}}+c_{6} \lambda_{i}
$$

The efficiency $a$ of the wind turbine can be derived from Equation (2). Where, $c_{1}, c_{2}, c_{3}, c_{4}, c_{5}, c_{6}$ are parameters of wind turbine, $\lambda$ is tip speed ratio which is a value of blade tip velocity divided by wind speed. The values of a often range from $0.45-0.5$ depends on wind turbines and $\lambda$ conditions. Within our study, $a$ we choose a value of 0.5 .

The annual energy $E$ can be converted from wind energy into electricity and can be expressed as:

$$
E=\int_{v_{\text {cut in }}}^{v_{\text {cut out }}} P f(v) 8760 \mathrm{~d} v
$$

Table 1. Comparison parameters from different data sources in the year of 2005.

\begin{tabular}{ccccc}
\hline & Speed standard deviation $(\mathrm{m} / \mathrm{s})$ & Mean speed & K of Weibull & C of Weibull \\
\hline A.R. & 4.09 & 9.91 & 3.4 & 3.35 \\
Model & 5.38 & 11.2 & 3.38 & 11.03 \\
DIRTH & 4.12 & 9.94 & 2.47 & 6.36 \\
DAS & 2.19 & 5.66 & 2.95 & 6.58 \\
Observation & None & 5.87 & & \\
\hline
\end{tabular}


When the wind speed $v$ is greater than rated speed, the output of wind turbine no longer increases. Hence, the values were taken as rated speed when the wind speeds of data exceed the rated speed.

Because the data is inconstant but a four-hour averaged data, the Equation (3) can be changed as:

$$
E=\sum_{v_{\text {cut in }}}^{v_{\text {cut out }}} P f(v) 8760 \Delta v
$$

where, $v_{\text {cut out }}$ is the cutout speed of the wind turbine, $v_{\text {cut in }}$ is the cut in speed of wind turbine; $f$ is the frequency of wind speed $v$.

$$
f(v)=\frac{k}{c}\left(\frac{v}{c}\right)^{k-1} \exp \left(-\left(\left(\frac{v}{c}\right)^{k}\right)\right)
$$

where, $k$ is shape parameter and $c$ is scale parameter. The values of $k$ and $c$ can be obtained with the following method [13],

$$
\begin{gathered}
k=\frac{\rho}{\mu}^{-1.086} \\
c=\frac{\mu}{\Gamma\left(1+\frac{1}{k}\right)}
\end{gathered}
$$

where $\mu$ is the expectation of the wind speed data of a certain place, $\rho$ is standard deviation of the wind speed data of a certain place, $\Gamma$ is function of Gamma. $\Gamma$ is very hard to calculate directly, therefore, it can be calculated by the empirical Equation (8) .

$$
\Gamma\left(1+\frac{1}{k}\right)=\left(0.568+\frac{0.434}{k}\right)^{\frac{1}{k}}
$$

The Equation (8) can be approximated the real equation with very high resolution when $k$ is larger than 1 and smaller than 3 . The error is no larger than $0.3 \%$.

Based on empirical power law relationship, the wind speed of 80 meter height can be obtained as following

$$
U_{80}=U_{71}\left(\frac{Z_{80}}{Z_{71}}\right)^{n}
$$

$U_{80}$ is the wind speed at 80 meter height above the sea level, $n$ is the power law exponent, as for the ocean, $n$ is $0.11, Z_{80}$ and $Z_{71}$ are the height above the sea level [14].

\section{Result Discussion}

\subsection{Annual Fluctuations of Power and Total Electrical Output from Wind Power}

In order to prevent the influence to landscape, radio and radar transmission and other human activities like shipping, fishing, wind farms should be built further away than $10 \mathrm{~km}$ off the coastline. According to research of Musial et al. [15], less than 33\% can be developed within the area between 9.3 and $37 \mathrm{~km}$ offshore, expanding $67 \%$ of offshore wind energy in the area further than $37 \mathrm{~km}$. In this paper, the wind energy distribution of distance from 0 to $250 \mathrm{~km}$ off the shore were studied and analyzed.

The Figure 1 and Table 2 show that:

Zhejiang area enjoys most wind energy resource in Chinese ocean area, more than 1.4 MW energy can be converted into electricity by the wind turbine and one wind turbine can generate an average of $1.8 \times 10^{4}$ $\mathrm{KWh} / \mathrm{year}$. Wind energy increases until 50 kilometers away from shore with distance, then decreases when the distance further away than 100 kilometers. The reason which causes this phenomenon is the Taiwan Strait. It's like a narrow tube which can increase wind speed when monsoon pass through narrow Taiwan Strait. Hence, the area which is 50 kilometer to 100 kilometer away from coast is preferable for wind farm sites.

The encircled Shandong peninsula and Korea peninsula prevent large variation of wind speed. Therefore, 


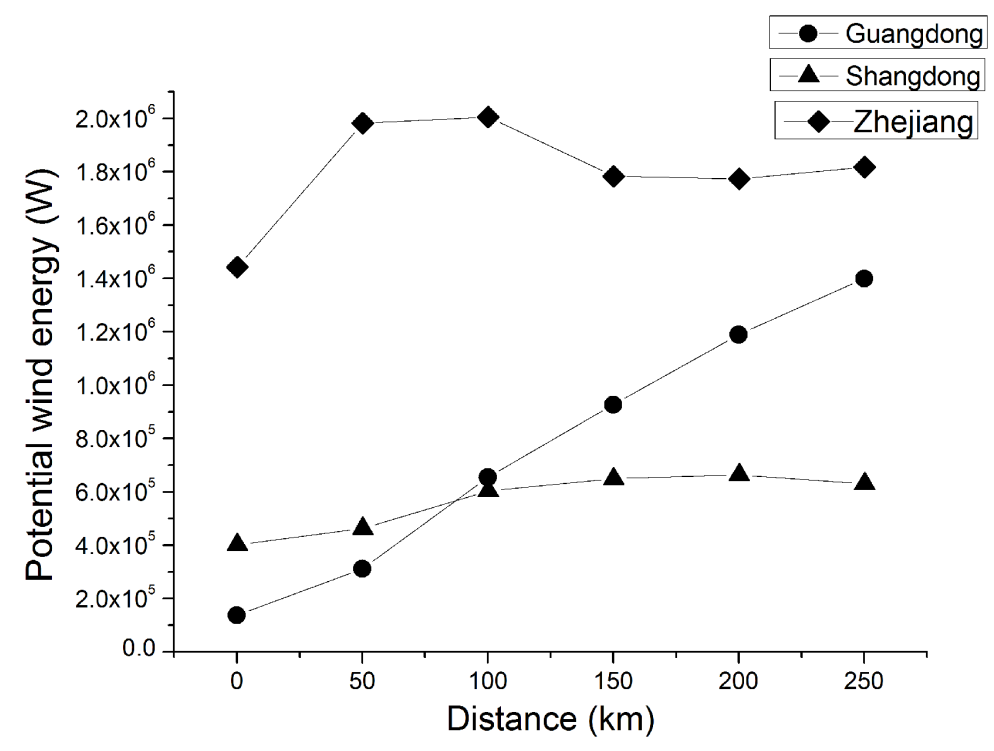

Figure 1. Potential wind energy changes with distance away from coast in three planning wind farm base.

Table 2. The annual output of electricity per wind turbine (KWh).

\begin{tabular}{ccccccc}
\hline Distance $(\mathrm{km})$ Place & 0 & 50 & 100 & 150 & 200 & 250 \\
\hline Guangdong & $1.36 \mathrm{E}+7$ & $1.13 \mathrm{E}+7$ & $8.89 \mathrm{E}+6$ & $6.44 \mathrm{E}+6$ & $3.15 \mathrm{E}+6$ & $1.37 \mathrm{E}+6$ \\
Zhejiang & $1.75 \mathrm{E}+7$ & $1.76 \mathrm{E}+7$ & $1.84 \mathrm{E}+7$ & $2.05 \mathrm{E}+7$ & $1.94 \mathrm{E}+7$ & $1.37 \mathrm{E}+7$ \\
Shandong & $5.79 \mathrm{E}+6$ & $6.24 \mathrm{E}+6$ & $6.28 \mathrm{E}+6$ & $5.9 \mathrm{E}+6$ & $4.45 \mathrm{E}+6$ & $3.8 \mathrm{E}+6$ \\
\hline
\end{tabular}

Wind energy varies slowly along the distance to coast with apparently less wind energy resource potential than Zhejiang area. Although there is an increase of up to $1 \mathrm{MW}$ from near shore areas to fares shore areas, considering building and maintaining cost , wind farms are recommended to build near coast areas.

Combination of near shore wind farm and far shore wind farms is most suitable for Guangdong area. The energy is increasing linearly with distance further away from the coast.

\subsection{Monthly Fluctuation in Three Places}

The electricity consumers measured their consumption monthly. Monthly wind energy potential is calculated to predict the electricity obligation of wind farm. Then the power grid company can determine the energy supply for every wind farm unit.

Chinese off shore monthly fluctuation characteristics are showed as Figure 2 and Figure 3, Zhejiang sea area is located in East Chinese Sea and near Taiwan Strait. During October and January, maximum wind energy, about more than 4 MW per wind turbine, can be extracted when north wind is prevailing affected by the Siberia high pressure center. Least wind energy value as approximately $1 \mathrm{MW}$ appears from May to August. There is a sharp increase of wind energy from September to October, at that time north wind begin to prevail in China. On the contrast, if the north wind prevailing stop in February, the wind energy potential decrease very fast from 4.5 MW to 2 MW. Different sites show same varying tendency of fluctuation of wind energy. Wind energy potential of coastline changes least in Zhejiang sea area than other places, average wind energy potential is around 1.5 MW in this area with amplitude of variation of less than 1.5 MW. Wind energy resources are rich in winter season while poor in summer and changes are dramatically in spring and autumn.

Amplitude of wind energy of off-coast of Guangdong area covers a range from less than 0.5 MW to 2 MW. During September, wind turbines extract most wind energy in most of the researching area, far shore area even can obtain energy of 2.5 MW from the wind. From June to July, least energy, only about 0.5 MW, can be converted into electricity. The fluctuation changes differently in near shore area and far shore area. The further from coastline, more drastically vary of wind energy potential. The characteristic in this area is caused by open sea 


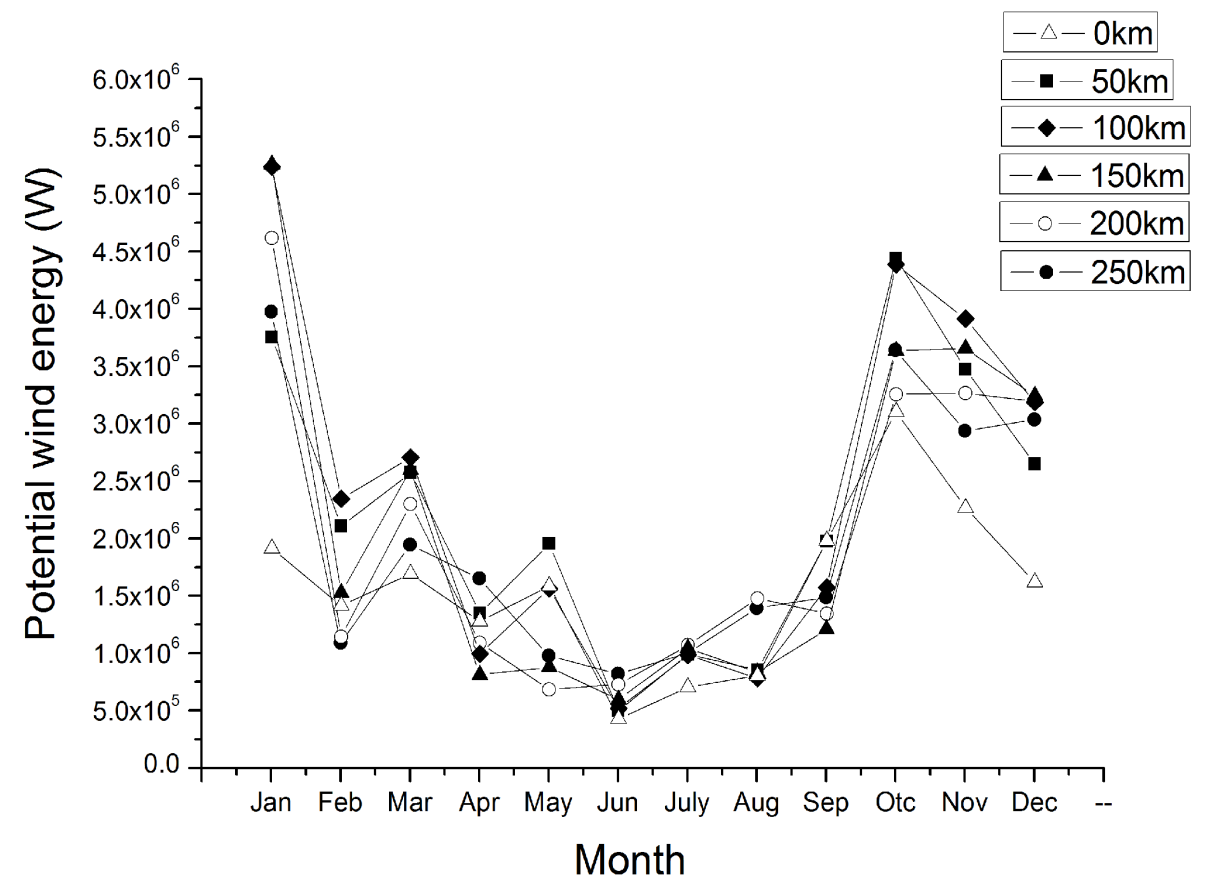

Figure 2. Monthly fluctuations in Zhejiang area.

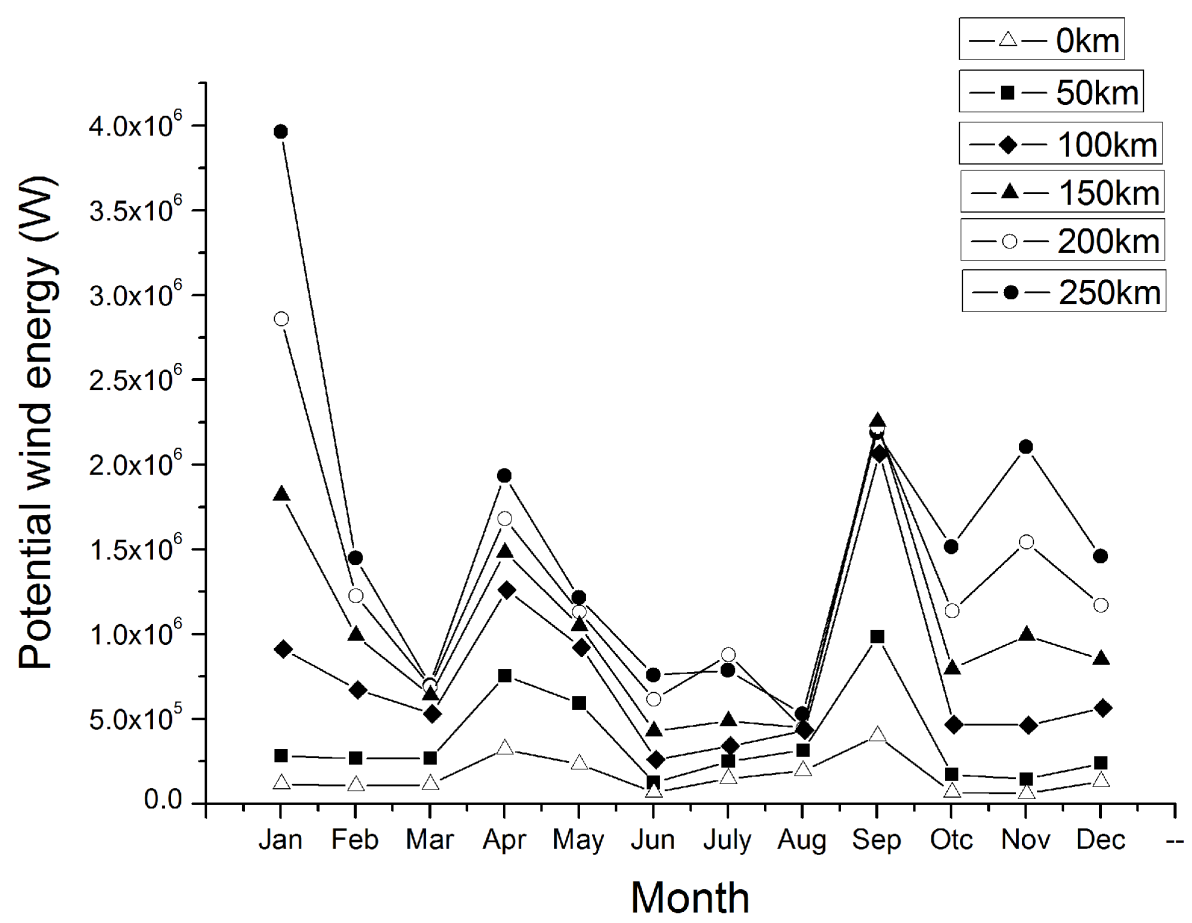

Figure 3. Monthly fluctuations in Guangdong area.

without large islands or continent which would decrease wind speed.

The wind energy potential is unstable in all the area of Bohai Sea of Shandong area as show in the Figure 4. Lowest value of wind energy appears in February. During the following month, wind energy potential increases from 0.2 MW to more than 0.5 MW in near shore area. Far shore wind energy is more firm or stable than that of near shore area, average of wind energy potential changes around $0.8 \mathrm{MW}$. 


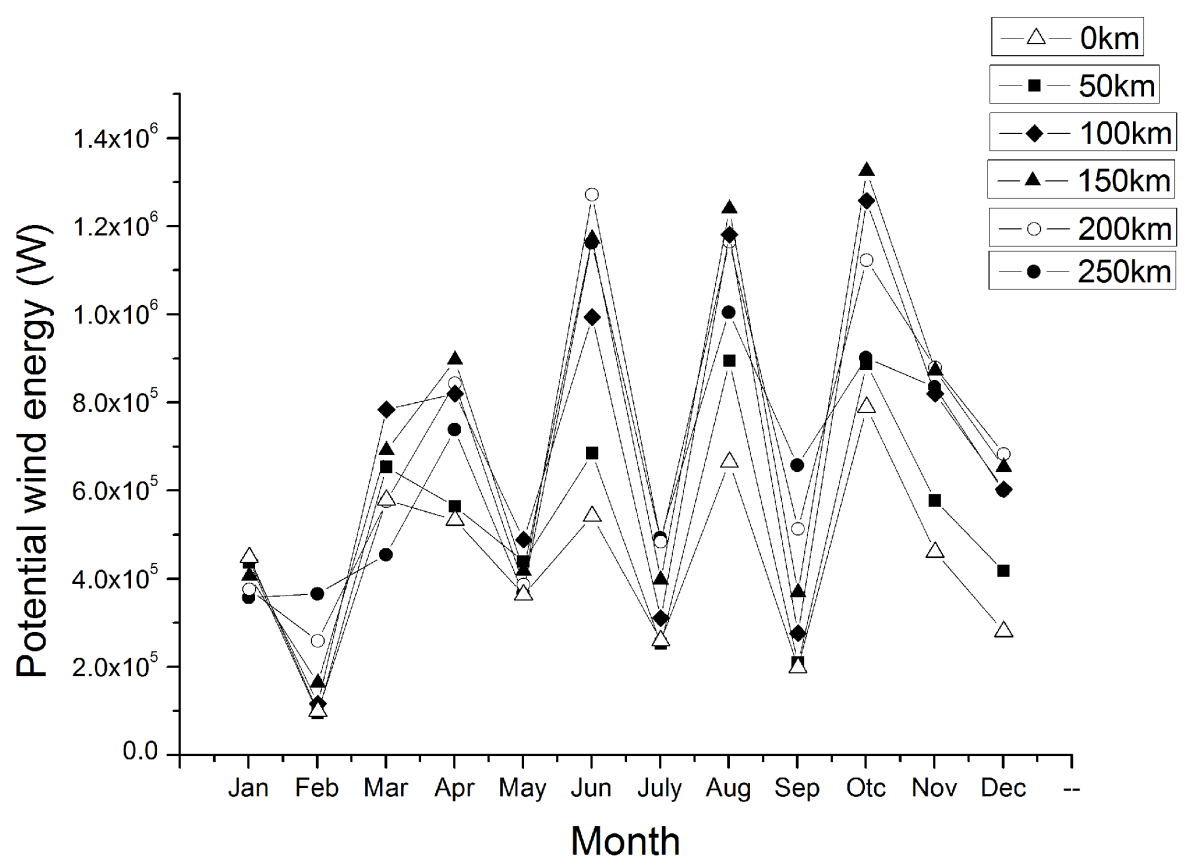

Figure 4. Monthly fluctuations in Shandong area.

\section{Layout of Wind Turbines}

In order to prevent the interaction of downstream and lateral wind turbines performance, a certain distance should be kept between ambient wind turbines. Previous research showed that less than 10 percent of energy loss is economically accepted for building a wind farm [16]. Robert-Zoltán Szász etc. proved that the lateral distance should be larger than 1 rotor diameter [17]. Experiments show that downstream distance should be set to at least 10 rotor diameters of wind turbine. For preventing the influence between wind turbines, a distance should be kept downstream-wisely and laterally, $10 \mathrm{D}$ and $3 \mathrm{D}$ separation are preferred [16].

For further increasing the efficiency of wind turbines, latest technology should be applied. Using wind-lens wind turbines can increase the number of wind turbines to convert more energy into electricity in a certain area because of reduced diameter of rotor of wind turbine. Wind lens-wind turbines can be set up much closer together with of factor of 2.25 compared with other kinds of wind turbine in area which is suitable for building wind farms. The increased power output of wind farm using wind-lens technology is a research topic to be evaluated in the future. Wind-lens wind turbines with property of wind concentration and accelerating the wind speed. That means that under the same rated power, the shape of wind lens type is smaller than ordinary ones. The research showed that the wind lens wind turbine has the advantage that the diameter of the wind turbine is only two third compared with of the common type [18].

\section{Concluding Remarks}

In this paper, the retrospective analysis data of GEOS-DAS were used to assess the Chinese offshore wind resources. Retrospective analysis data can be more effectively used for the assessment of spatial and temporal variation in offshore wind resource than remote sensing data when direct measured data are hard or extreme expensive to get. There is rich wind resource supply in Zhejiang offshore area while Shandong area is not rich in wind energy as the other two places.

Wind lens-type wind turbines with shorter diameter of wind turbine than other type wind turbine can cut down the transport and assembling cost resulting from decrease of weight of wind turbine.

Further development of the technology of wind energy is expected to reduce the cost of the offshore wind farms in the near future. Due to its advantages in offshore farms, it is significant for construction of offshore wind farms. The research can be applied in the scope of siting wind farm and predict the wind energy change within a year. 


\section{Acknowledgements}

The authors thank the program of China Scholarships Council (CSC) for financial support. We are indebted to Mary C. Green from Data and Information Services Center of National Aeronautics and Space Administration (NASA) for providing the GEOS-5 data. We also appreciate Uli GLTENBOTT for helpful discussions and refinement of the paper.

\section{Funding}

This work was supported by JSPS KAKENHI Grant Number 24246161.

\section{References}

[1] The World Bank Group (2010) China: Meeting the Challenges of Offshore and Large-Scale Wind Power. The World Bank Group, Washington DC.

[2] Li, J.F., Shi, P.F. and Gao, H. (2010) 2010 China Wind Power Outlook. http://gwec.net/wp-content/uploads/2012/06/wind-report0919.pdf

[3] Environmental Change Institute (2005) Wind Power and the UK Wind Resource. Environmental Change Institute, Oxford.

[4] Lu, X. and McElroy, M.B. (2009) Global Potential for Wind-Generated Electricity. Proceedings of the National Academy of Sciences, 106, 10933-10938. http://dx.doi.org/10.1073/pnas.0904101106

[5] OECD/International Energy Agency (2011) Technology Roadmaps: China Wind Energy Development Roadmap 2050. International Energy Agency, Paris.

[6] UNFCCC/CCNUCC (2012) United Nations Framework Convention on Climate Change Revision to the Approved Consolidated Baseline Methodology. ACM0002, 6-11.

[7] Liu, C. and He, X. (2003) The Analysis on the Statistical Character of QuikSCAT Scatteromter Winds and Strong Wind Frequency Using Remote Sensor Data from QuikSCAT. Journal of Tropical Meteorology, 19, 107-117.

[8] Xu, J.W., Luo, Y., Zhang, X.Z. and Zhu, R. (2008) China Offshore Wind Energy Resources Assessment with the QuikSCAT Data. Remote Sensing of the Ocean, Sea Ice, and Large Water Regions, 13 October 2008, 71050B.

[9] Rienecker, M.M. (2007) The GEOS-5 Data Assimilation System-Documentation. NASA Publication, USA.

[10] Yu, D.Y., Liang, J., Han, X.S. and Zhao, J.G. (2011) Profiling the Regional Wind Power Fluctuation in China. Energy Policy, 39, 299-306. http://dx.doi.org/10.1016/j.enpol.2010.09.044

[11] NASA. The GEOS-5 System. http://gmao.gsfc.nasa.gov/GEOS/

[12] Archer, C.L. and Jacobson, M.Z. (2007) Supplying Baseload Power and Reducing Transmission Requirements by Interconnecting Wind Farms. Journal of Applied Meteorology and Climatology, 46, 1701-1717. http://dx.doi.org/10.1175/2007JAMC1538.1

[13] Chen, J.-C., Duan, W. and Ye, F. (2011) Research on the Methods Estimating Weibull Distribution Parameters. Machinery Design \& Manufacture, 18, 73-74. (in Chinese)

[14] Hsu, S.A., Meindl, E.A. and Gilhousen, D.B. (1994) Determining the Power-Law Wind-Profile Exponent under NearNeutral Stability Conditions at Sea. Journal of Applied Meteorology, 33, 757-772. http://dx.doi.org/10.1175/1520-0450(1994)033<0757:DTPLWP>2.0.CO;2

[15] Musial, W. and Butterfield, S. (2004) Future for Offshore Wind Energy in the United States. Energy Ocean 2004, Palm Beach, 28-29 June 2004.

[16] Chen, K. and He, D.-X. (2003) The Study for the Wake Model of Wind Turbine and the Wake Effects on the Performance of Wind Turbine. Experiments and Measurements in Fluid Mechanics, 17, 84-87.

[17] Szasc, R., Kruger, J. and Fuchs, L. (2011) Numerical Evaluation of the Interaction of Two Wind Turbines for Varying Lateral Spacing. European Wind Energy Annual Event, Bruxelles, 3 November 2011. http://proceedings.ewea.org/annual2011/allfiles2/1107_EWEA2011presentation.pdf

[18] Ohya, Y. and Karasudani, T. (2010) A Shrouded Wind Turbine Generating High Output Power with Wind-Lens Technology. Energies, 3, 634-649. http://dx.doi.org/10.3390/en3040634 